\title{
Experimental Study on the Influence Mechanism of the Structural Plane to Rockbursts in Deeply Buried Hard Rock Tunnels
}

\author{
Guangtan Cheng $\mathbb{D}^{1,2}$ Jian Zhang $\mathbb{D}^{1},{ }^{1}$ Qiang Gao $\mathbb{D}^{\mathrm{D}},{ }^{1}$ and Chuanxiao Liu ${ }^{1}{ }^{1}$ \\ ${ }^{1}$ College of Water Conservancy and Civil Engineering, Shandong Agricultural University, Tai'an 271018, China \\ ${ }^{2}$ State Key Laboratory of Geomechanics and Geotechnical Engineering, Institute of Rock and Soil Mechanics, \\ Chinese Academy of Sciences, Wuhan 430071, China \\ Correspondence should be addressed to Jian Zhang; zhangj614@163.com and Qiang Gao; gaoqiang@sdau.edu.cn
}

Received 6 April 2021; Accepted 29 April 2021; Published 10 May 2021

Academic Editor: Zhigang Tao

Copyright (c) 2021 Guangtan Cheng et al. This is an open access article distributed under the Creative Commons Attribution License, which permits unrestricted use, distribution, and reproduction in any medium, provided the original work is properly cited.

\begin{abstract}
During the excavation of a large number of deeply buried tunnels and mining projects, rockburst disasters occur frequently due to the complex geologic environment in deep underground, including high initial geostress, adverse tectonic actions, and excavation disturbance. Many rockbursts have been found to be induced by some small-scale structural planes in the area around the tunnels during the construction of Jinping II hydropower station. In order to study the influence mechanisms of the structural plane to rockbursts, the physical simulation tests of rockbursts under biaxial stress conditions are carried out using marble samples by considering different relative positions of the structural plane with tunnels, namely, in tunnel spandrel, in tunnel sidewall, and at the intersection with the tunnel. The digital image correlation (DIC) technique is used to trace the evolution of the deformation on the surface and the rockburst process of the marble sample. The results reveal that three types of rockbursts are identified, namely, fault-slip rockburst, split bulking rockburst, and shear rupture rockburst, and their evolution processes are reproduced. The presence of small-scale structural planes in the vicinity of deep tunnels could be one of the major influence factors in triggering rockbursts. The findings could provide helpful references for predicting the development process and the design of burst-resistant measures for this type of rockbursts.
\end{abstract}

\section{Introduction}

As the foundation engineering construction and the resource development are progressing to greater depths, the frequency of rockburst increases remarkably. Rockburst disasters have been the significant threat to the safety construction of deep underground rock mass engineering. Besides rockbursts occurring easily in hard intact rock masses, small-scale structural planes have been found to play a significant role in inducing rockburst in deeply buried hard rock tunnels [1-5]. This type of rockburst related to structural planes is referred to as the structure-type rockburst. For instance, an extremely intense rockburst (often referred to as the 11.28 rockburst because of the date on which it occurred) took place in a drainage tunnel of the Jinping II hydropower station. As a result of this event, seven workers were killed and a TBM machine was totally destroyed causing significant economic losses. After this rockburst, a rigid structural plane subparallel to the tunnel axis which strike NWW and dip about $50^{\circ}$ was exposed at the boundary of the rockburst. All the rock masses beneath the structural plane were collapsed, creating a "V"-shaped failure zone, as illustrated in Figure 1 [6]. Postmortem analysis suggested that this rockburst event might be induced by the sudden sliding failure of the structural plane caused by excavation activities.

In recent decades, although extensive research studies have been conducted to investigate the mechanism of rockbursts, the influence mechanism of structural plane on rockbursts is pretty rare and still unclear. Williams [7] recorded a rockburst that is caused by the movement along an argillite bed first observed after the macroseismic 

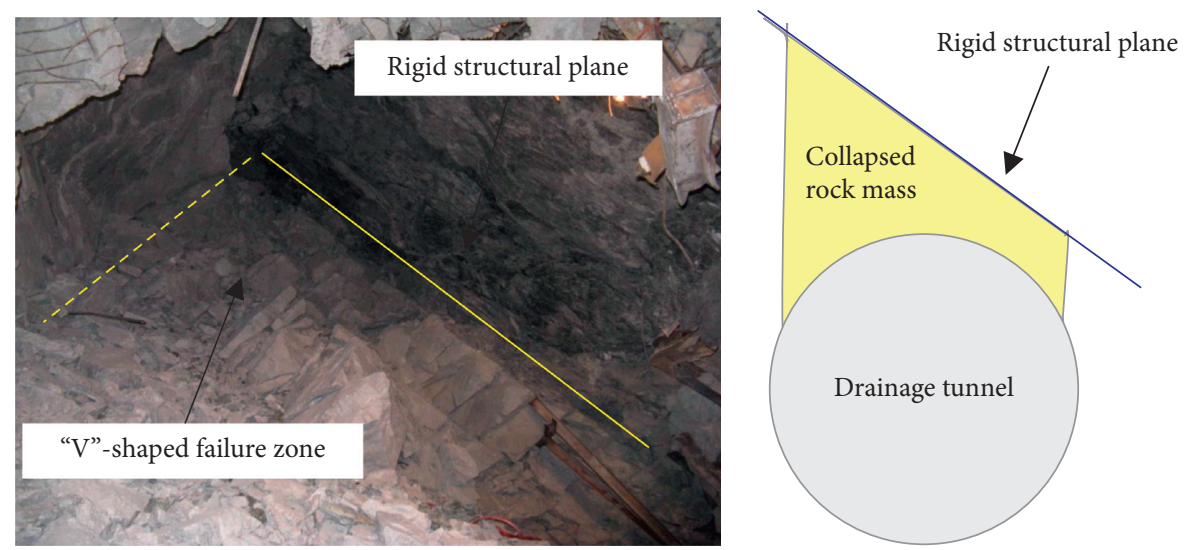

Figure 1: The 11.28 rockburst in drainage tunnel and exposed rigid structural plane [6].

monitoring system had been installed. Ortlepp and Stacey [8] classified the rockburst by main source mechanisms into five types: strain-bursting, buckling, face crush, shear rupture, and fault-slip. The authors supposed that the last two source mechanisms of rockbursts represented shear failure on a plane different from those of the first three and that shear failure of a plane may induce rockburst. White and Whyatt [9] suggested that slip movements of a steeply dipping fault towards a nearby stope increases stress at the margins of stopes, which resulted in rockbursts. Many researchers revealed that fault slip can generate seismic waves that could inflict rockburst [10-12]. Castro et al. [13] analysed the influences on fault slip of four possible factors, including unclamping, daylighting, stress rotation, and pillar shear. Zhang et al. [14] analysed the impact of macrogeological conditions (e.g., the tunnel depth, the fold, and the fault) on rockbursts occurring on tunnel floor at Jinping II hydropower station. Zhou et al. [15] conducted laboratory direct shear tests of structural planes with different asperity heights to explore the source mechanism of rockbursts caused by structural planes. In above studies, the rockburst mechanisms induced by the structural plane were all investigated after the rockburst event. There are rare model tests to simulate the evolution of rockbursts influenced by the structural plane.

More than 20 rockburst cases influenced by structural planes are listed and the rockburst characteristics are presented during the excavation of Jinping II headrace tunnels [1]. Numerical analyses have also been conducted to simulate the movements of fault-slip and the generated seismic waves resulting from mining activities [16-21]. To date, a number of studies have been conducted analytically and numerically to investigate the rockbursts induced by fault slip. However, the influence mechanism of small-scale structural planes on rockbursts has not been sufficiently studied.

In this paper, physical model experiments in laboratory are carried out for clear observation of the rockburst evolution process influenced by small-scale structural planes. The evolution processes are recorded simultaneously by the DIC technique. The structural-type rockburst caused by shearing is simulated by the means of UDEC software. A discussion of the results and the future research plan in dealing with the shortage of current models is presented.

\section{Model Sample Preparation and Testing Procedure}

Rock masses prone to rockbursts are typically stiff, strong, and brittle, with uniaxial compressive strength of 100-400 MPa with Young's modulus > $20 \mathrm{GPa}$ [22]. Therefore, the hard brittle marble materials were used as the model samples considering their burst-prone characteristics under high compressive stresses, and the basic mechanical parameters of this marble sample are listed in Table 1. The thinplate marble samples with dimensions of $150 \mathrm{~mm} \times 150 \mathrm{~mm} \times 30 \mathrm{~mm}$ were cut from a long piece of marble collected from a building material market. A circular hole with a diameter of $30 \mathrm{~mm}$ served as the excavated tunnel was drilled at the center of the sample. A pinhole was drilled at the position of $5 \mathrm{~mm}$ away from the tunnel boundary for a thin wire getting through. The structural plane with $45 \mathrm{~mm}$ in length was cut with the thin wire saw about $1 \mathrm{~mm}$ in diameter. According to different relative positions of the structural plane and the tunnel sections, three types of model samples were prepared, as shown in Figure 2. For model samples A, B, and C, the structural plane was located in the tunnel spandrel, in the tunnel sidewall, at the intersection with the tunnel, respectively.

The model tests were carried out on the Rock Biaxial Loading and Macro-Mesoscopic Measurement System at the Institute of Rock and Soil Mechanics, Chinese Academy of Sciences. The experimental system is composed of biaxial loading system and deformation measurement system, as shown in Figure 3. The maximum loading capacity and travelling displacement are $1000 \mathrm{kN}$ and $200 \mathrm{~mm}$, respectively. The deformation measurement system is equipped with two high-speed cameras, two LED lights, and 3D-DIC (digital image correlation) processing software, and the measurement accuracy of strain is $10^{-5}$. When the test began, a horizontal stress was first applied to $5 \mathrm{MPa}$ at a rate of $0.1 \mathrm{kN} / \mathrm{s}$ and kept constant. Then a normal stress was applied until the ultimate failure of samples at a rate of $0.002 \mathrm{~mm} / \mathrm{s}$. Before the test, a random grey intensity 
TABLE 1: Basic mechanical parameters of the marble used in this study.

\begin{tabular}{|c|c|c|c|c|}
\hline Type of material used & $\sigma_{c}(\mathrm{MPa})$ & $\sigma_{t}(\mathrm{MPa})$ & $E(\mathrm{GPa})$ & $\mu$ \\
\hline Marble & 126.06 & 1.63 & 51.59 & 0.23 \\
\hline
\end{tabular}

$\sigma_{c}, \sigma_{t}, E$, and $\mu$ are uniaxial compression strength, the uniaxial tensile strength, elastic modulus, and Poisson ratio, respectively.

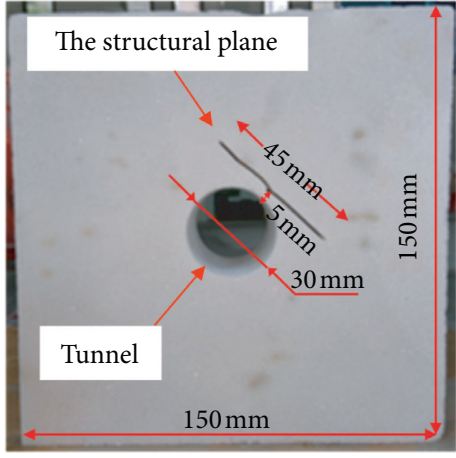

(a)

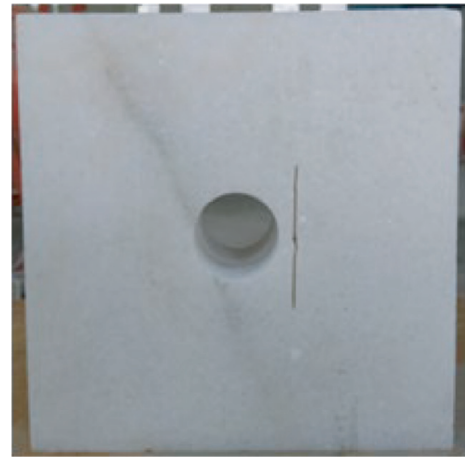

(b)

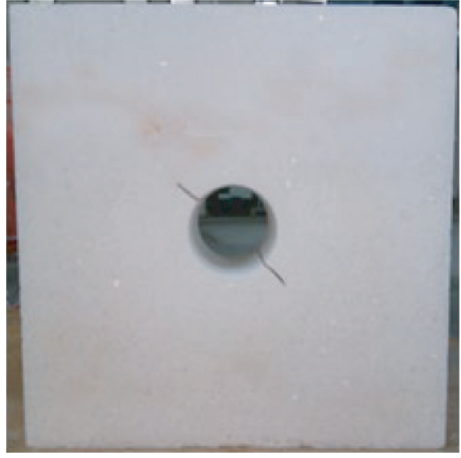

(c)

FIgURE 2: Three types of marble model samples. (a) The structural plane located in the tunnel spandrel. (b) The structural plane located in the tunnel sidewall. (c) The structural plane intersected with the tunnel.

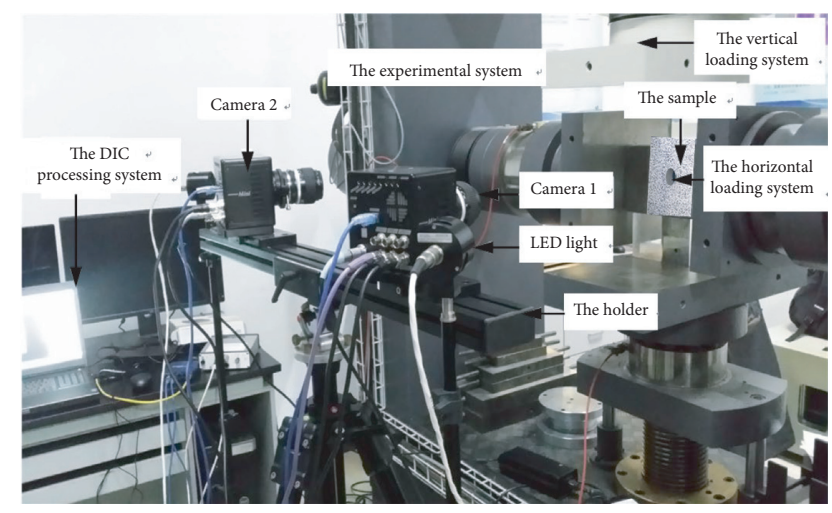

FIgure 3: The Rock Biaxial Loading and Macro-Mesoscopic Measurement System.

distribution is made by spraying black paint and white paint onto the surface of the thin-plate sample for DIC analysis.

\section{Model Test Result Analysis}

3.1. Stress-Strain Curves. The axial stress versus axial strain curves of three types of model samples under biaxial pressure are illustrated in Figure 4. The results show that the stress-strain curves can be divided into four main regions and the typical points are marked on the curves: elastic deformation region, stable crack propagation region, unstable crack propagation region, and postpeak region [23]. Before the axial stress is applied, most existing, open, and appropriately oriented microcracks in the model sample are effectively closed due to the compaction of the applied horizontal stress of $5 \mathrm{MPa}$. In the initial region, the axial stress increases linearly with the increase of axial strain and the marble sample is presumed to be a linear, homogeneous, elastic material. At the end of elastic deformation region, the curve has an inflection point and stable crack propagation begins, which indicate more microcracks start to form and propagate when the marble sample is loaded beyond the threshold at the inflection point. With the occurrence of more and more new cracks, the adjacent microcracks start to coalesce to form macroscopic fractures. After the peak stress is reached, a significant stress drop happens abruptly, indicating a sudden release of the strain energy stored in the marble sample. From the analysis of stress-strain curves and the evolution of cracks, it can be inferred that the shear failure of macrocracks may occur or even a rockburst may be induced.

Table 2 summarizes the stress and strain thresholds between different stages of stress versus strain curves shown in Figure 4 for three types of model samples. It is seen that the crack initiation threshold is approximately 0.3 times the peak stress and the onset of the crack damage starts at the stress levels of about 0.8 times the peak stress. This result is in keeping with those studies [24-27], which showed that $\sigma_{c i} / \sigma_{p}$ and $\sigma_{c d} / \sigma_{p}$ are about $0.3-0.5$ and $0.7-0.8$ times the peak compressive strength, respectively.

The shaded area below the stress-strain curve represents the strain energy stored during the loading process in the prepeak region, as shown in Figure 4. The amount of the releasable energy could be approximately estimated by the area encompassed by the triangle below the stress-strain curve, namely, a half of $\sigma_{p}$ times $\varepsilon_{p}$ in Table 2 . The peak strain of three types of model samples is $60.20,76.93$, and $90.76\left(\times 10^{-4}\right)$, which indicate model sample $A$ has the smallest peak strain and may be more prone to burst than model samples B and C under the same conditions. 


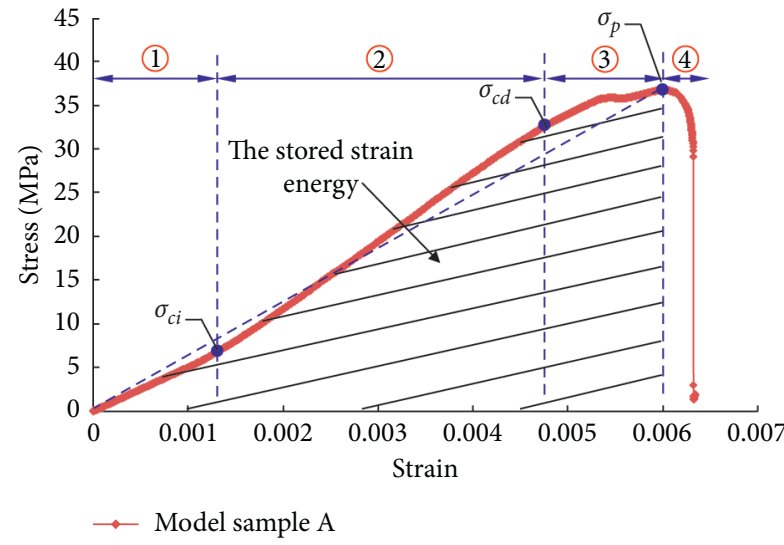

(a)

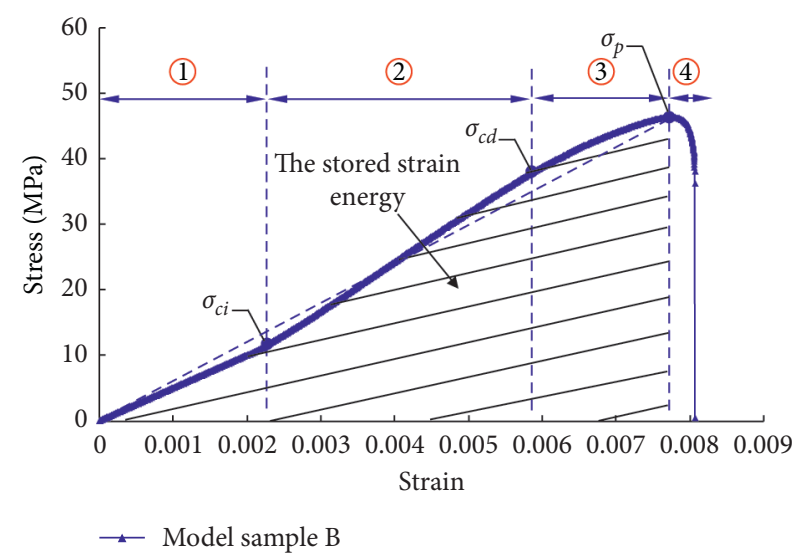

(b)

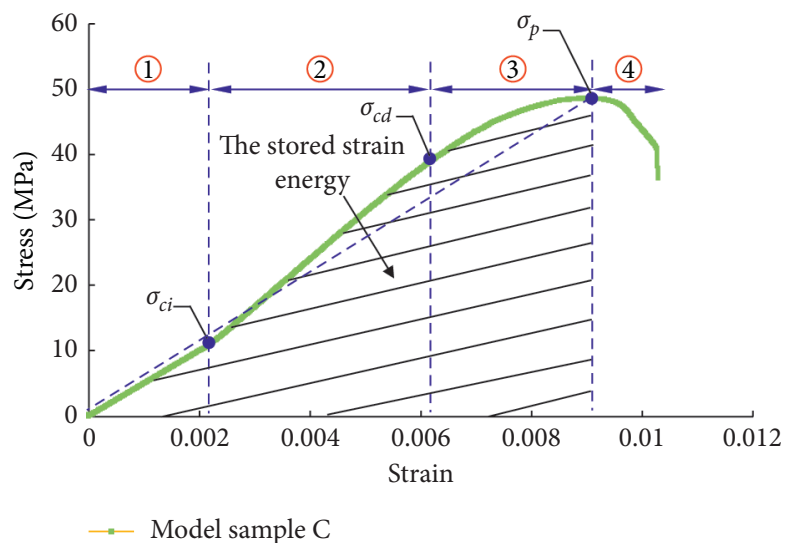

(c)

FIGURE 4: Curves of stress versus strain of three types of model samples: (a) model sample A; (b) model sample B; (c) model sample C (1), (2), (3), and (4) indicate the elastic deformation stage, stable crack propagation stage, unstable crack propagation stage, and postpeak stage) (after [23]).

TABLE 2: The stress and strain threshold between different stages of stress versus strain curves for three types of model samples.

\begin{tabular}{lcccccc}
\hline Type of model samples & $\sigma_{c i}(\mathrm{MPa})$ & $\sigma_{c d}(\mathrm{MPa})$ & $\sigma_{p}(\mathrm{MPa})$ & $\varepsilon_{p}\left(10^{-4}\right)$ & $\sigma_{c i} / \sigma_{p}$ & $\sigma_{c d} / \sigma_{p}$ \\
\hline Model sample A & 8.72 & 29.56 & 36.71 & 60.20 & 0.24 \\
Model sample B & 12.61 & 37.53 & 46.27 & 76.93 & 0.27 \\
Model sample C & 16.12 & 39.71 & 48.57 & 90.76 & 0.33 \\
\hline
\end{tabular}

$\sigma_{c i}, \sigma_{c d}, \sigma_{p}$, and $\varepsilon_{p}$ are the crack initiation stress, that is, the elastic limiting stress in this paper, the crack damage stress, the peak compressive strength, and the peak strain, respectively.

However, model sample $\mathrm{C}$ presents the biggest peak stress and also has the largest strain energy stored, followed by model samples $B$ and $A$, which may result in the highest rockburst hazard after release by the rapid stress drop [16]. The results could provide meaningful references for predicting the occurrence time and intensity of structural-type rockbursts according to the attitude of the structural plane.

3.2. Evolution Processes of Structural-Type Rockbursts. The rockburst evolution processes of three types of model samples are illustrated in Figure 5. According to the influence mechanism of structural planes and the model testing results, three types of structural-type rockbursts can be reproduced using model samples A, B and C, namely, the fault-slip rockburst, buckling rockburst, and shear rupture rockburst, respectively.

The evolution process of fault-slip rockburst experienced four main stages: quiet stage, crack initiation and propagation stage, shear slip stage, and rockburst stage, as illustrated in Figure 5(a), which is corresponded with the main regions of stress versus strain curves shown in Figure 4 . The quiet stage represents the closure of existing cracks and the storing of the strain energy with the initial loading. Due to the increasing axial loading and the opening of the tunnel, the tangential stress is concentrated in the surrounding area of the tunnel beneath the structural plane, while cracks are appeared at both ends of the structural plane and propagate 

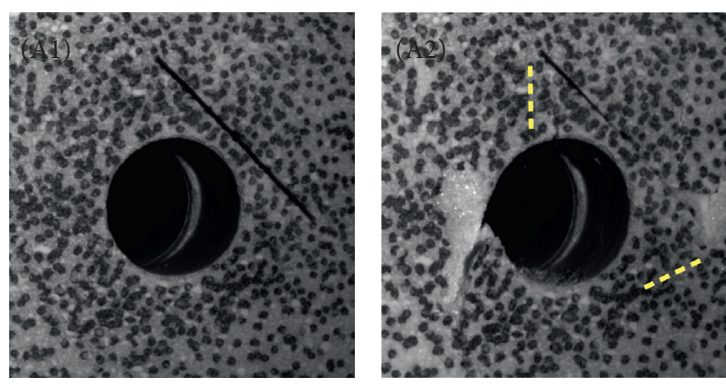

(a)
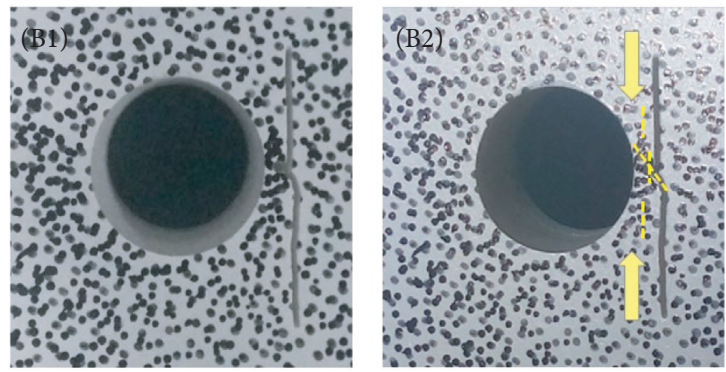

(b)
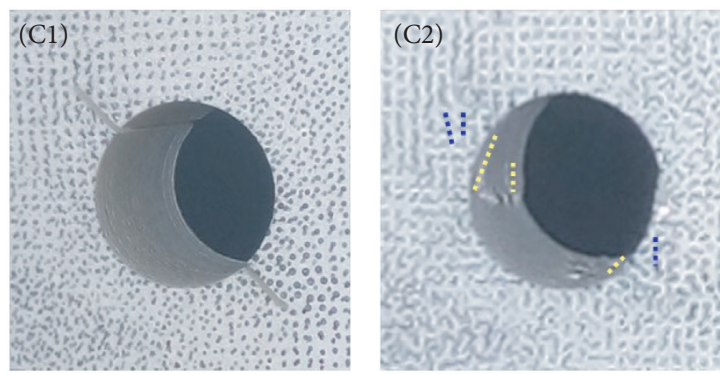
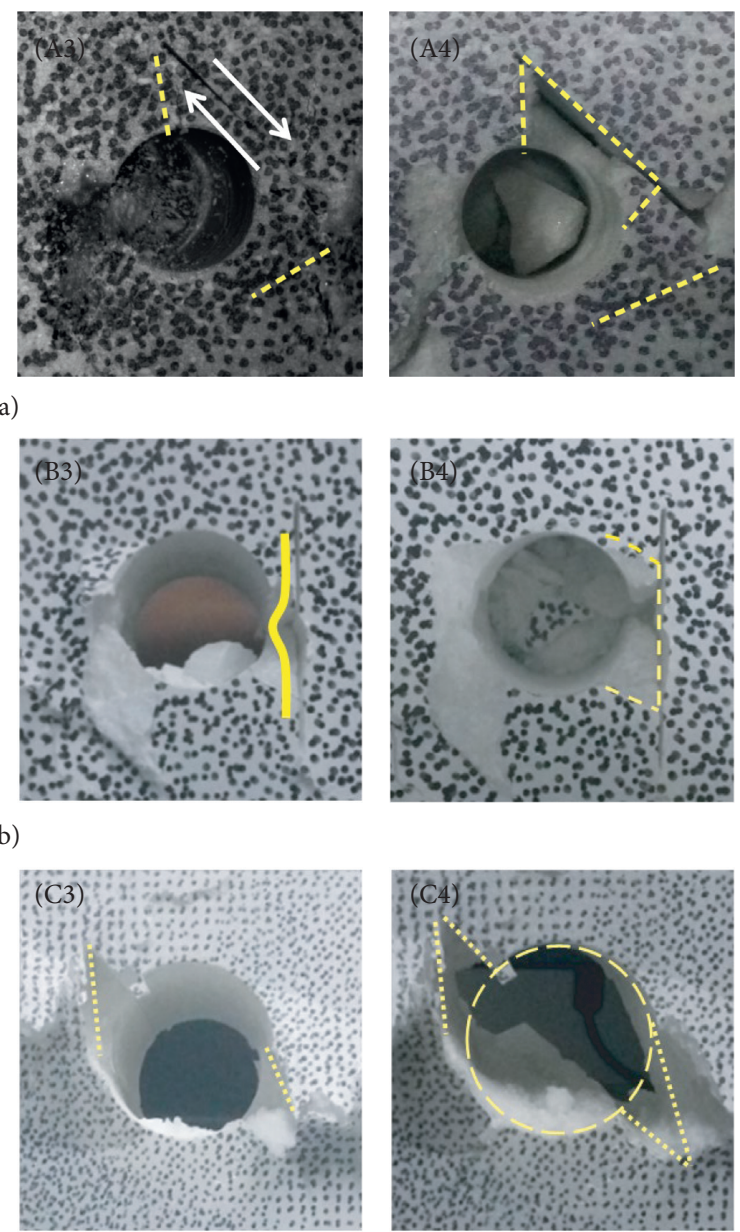

(c)

FIGURE 5: The rockburst evolution processes of three types of model samples: (a) fault-slip rockburst, (b) buckling rockburst, and (c) shear rupture rockburst.

towards the tunnel, as denoted by the yellow dotted lines in picture (A2) of Figure 5(a). When the shear stress exceeds the shearing resistance on the structural plane, shear slip initiates along the structural plane and the tensile fractures are caused in the rock masses beneath the structural plane, as shown in picture (A3) of Figure 5(a). Pictures (A3) and (A4) of Figure 5(a) show the violent ejection of rock factures towards the opening tunnel induced by the shock waves resulting from the stress drop in Figure 4 and a rockburst notch is formed after the event, as enclosed by the yellow dotted line. The final failure modes can well reflect the 11.28 rockburst occurred in deeply buried rock engineering (Figure 1).

The buckling rockburst process also involves four stages: quiet stage, crack initiation and propagation stage, splitting and bending stage, and rockburst stage, as illustrated in Figure 5(b). At the second stage, due to the influence of the vertical structural plane, the increasing axial loading can result in a rapid increase in the tangential stress between the tunnel and the structural plane. Then most of cracks with vertical orientation are caused by the axial stress concentration, as shown in picture (B2) of Figure 5(b). With the propagation and connection of more vertical cracks, many thin rock slabs subparallel to the structural plane are generated in the right sidewall. Due to the sustained stress accumulation and sudden stress drop, the thin slabs' buckling occurs, as shown in picture (B3) of Figure 5(b). Finally, the rock slabs at the right sidewall, which are separated from the surrounding rock mass by fractures, are carried or ejected into the tunnel by the stress waves, creating a rockburst pit, as illustrated in picture (4) of Figure 5(b).

Figure 5(c) shows that the evolution process of shear rupture rockburst can be described in four stages: quiet stage, crack initiation and propagation stage, shear rupture stage, and rockburst stage. Abundant cracks appear in the surrounding rock around the structural plane under the influence of the stress concentration, as shown in picture (C2) of Figure 5(c). When shear failure occurs along the structural plane, tensile fractures appear in the lower or upper part and the released energy from stress drop may lead to their ejection into the tunnel. After the rockburst, two "V"-shaped pits are formed with the structural plane as a boundary, as enclosed by yellow dotted lines in the picture (C4) of Figure 5(c). 


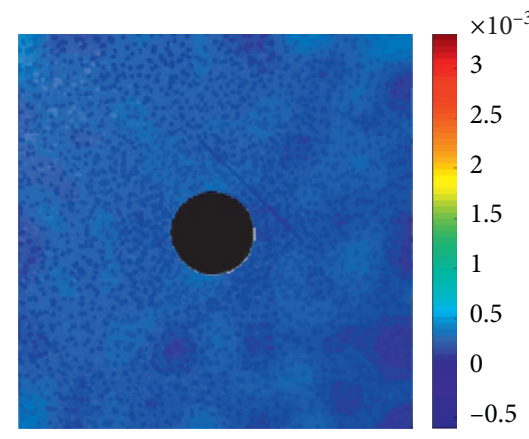

(a)

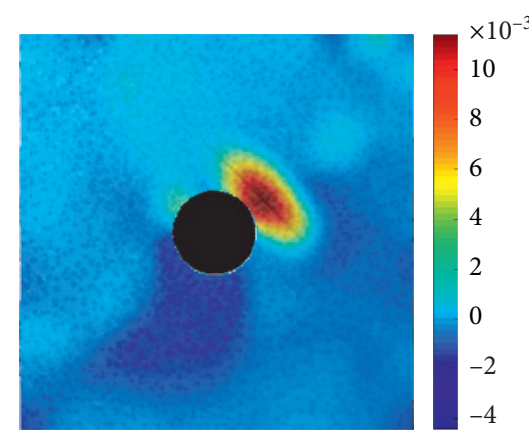

(d)

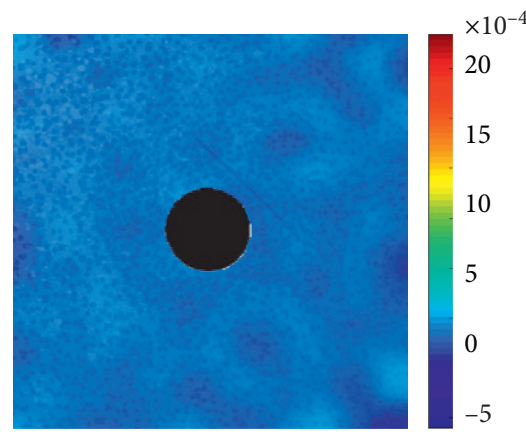

(b)

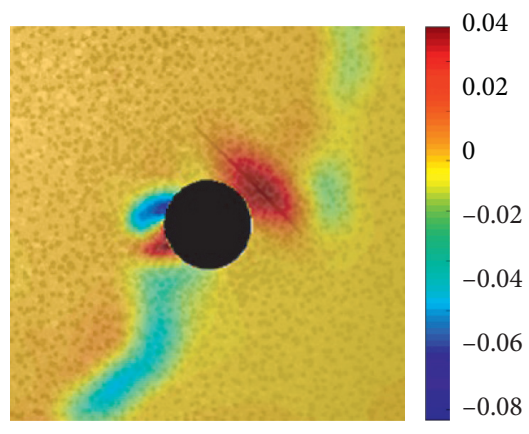

(e)

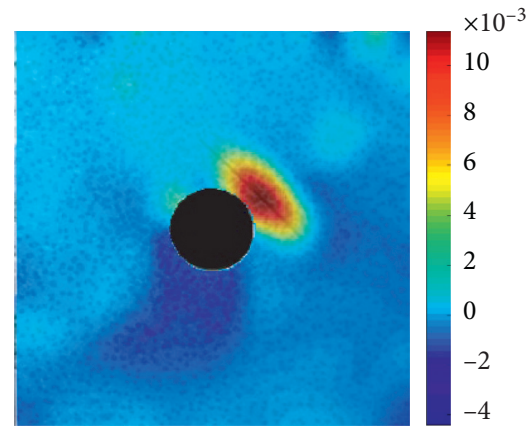

(c)

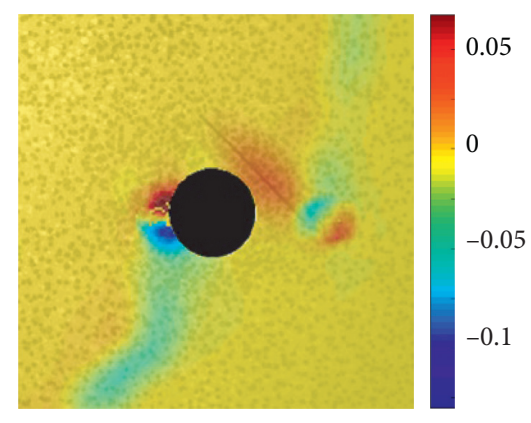

(f)

Figure 6: The shear strain contours of model sample A at different test stages: (a) $83 \mathrm{sec}$. (b) $87 \mathrm{sec}$. (c) $299 \mathrm{sec}$. (d) $305 \mathrm{sec}$ (e) $307 \mathrm{sec}$. (f) $308 \mathrm{sec}$.

According to the results of stress-strain curves and evolution processes, it can be concluded that the typical characteristics of structural-type rockbursts, including the location, time, intensity, and damage pit shape, are significantly affected by the control of stiff structural planes. Therefore, more attentions should be paid to the influences of the structural planes during the excavation of deep tunnels so as to prevent and mitigate rockburst damage.

3.3. Strain Fields of Structural-Type Rockbursts. As one of the most used optical and noncontact techniques for measuring material deformations, digital image correlation (DIC) is applied to trace the deformation and rockburst process of the model samples. A sequence of high-resolution images of the sample surface is captured by two high-speed cameras at a speed of five frames per second during the test. Then the displacement field or strain field of the sample surface can be obtained at any given moment by DIC analysis. In this paper, we emphasize on understanding the influence mechanism of the structural plane on fault-slip rockburst using the DIC technique. The shear strain fields of model sample A at different temporal steps are shown in Figure 6, illustrating the evolution process of rock deformations during the whole loading test. At initial loading, Figure 6(a) presents the shear strain on the whole surface of the sample is very small and no obvious strain concentration is observed when the sample is considered in elastic state. As the loading increases, obvious shear strain localization occurs in the middle part of the structural plane, as shown in Figures 6(c) and 6(d), which identify that the shear slip appears on the structural plane and triggers the subsequent rockburst, as shown in Figure 5(a). At the rockburst stage, as is noticed in Figure 6(f), shear strain concentration is situated at the left sidewall and beneath the structural plane, which is similar to the final failure characteristic of the sample, as shown in picture (A4) of Figure 5(a).

3.4. Numerical Analysis of 11.28 Rockbursts. In order to reproduce the continuous-to-discontinuous process and further understand the fracture mechanism of the rockburst influenced by the structural plane, numerical analysis was carried out based on the 11.28 rockburst by using universal distinct element code (UDEC) software. For the sake of simplicity, a two-dimensional elastoplastic model was established in plane strain condition and the initial geostress condition is the same as that of the 11.28 rockburst in situ with reference to the study of Zhang et al. [28]. Figure 7 shows the evolution process of the 11.28 rockburst. In the initial step, there are no obvious fractures occurring, as shown in Figure 7(a). At the 1560th steps, large amounts of fractures occur and are localized in the tunnel vault beneath the structural plane. The local place is collapsed and some fractured rock masses are detached from the tunnel vault, as shown in Figure 7(b). Abundant broken rocks have poured into the tunnel and the final state is presented in Figure 7(c). A damage pit is generated and it is bounded by the structural plane. Comparison between the results shown in Figure 7(c) and Figure 1 indicates that the geometry of the rockburst pit 


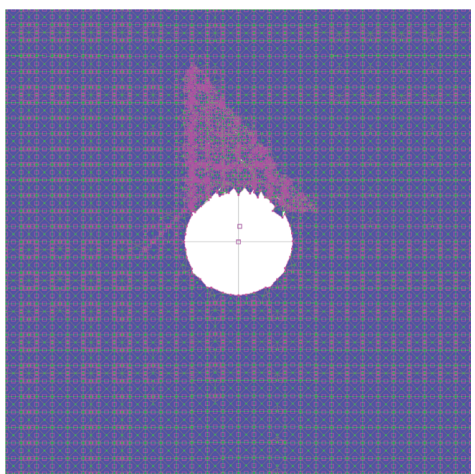

(a)

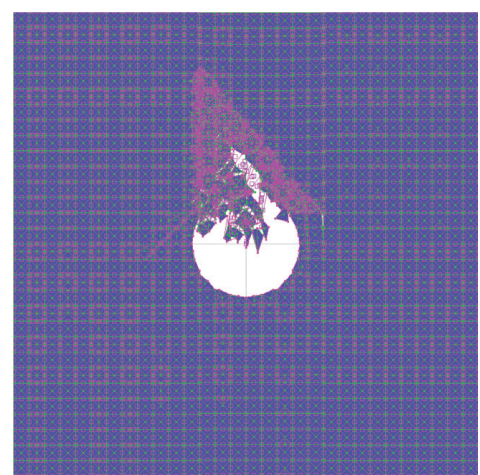

(b)

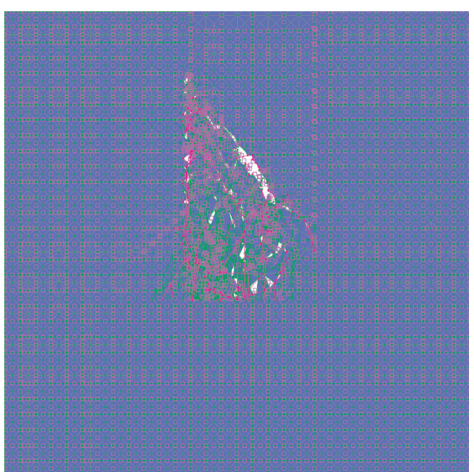

(c)

FIGURE 7: The evolution process of the 11.28 rockburst at different steps: (a) 150th step. (b) 1560th step. (c) 2590th step.

obtained from numerical results shows a strong agreement with the practical results of the 11.28 rockburst.

\section{Discussion}

For simplicity, a biaxial model test was performed using small sized marble samples with dimensions of $150 \mathrm{~mm} \times 150 \mathrm{~mm} \times 30 \mathrm{~mm}$, which is not exactly consistent with the site conditions. For further study, a true triaxial model test will be conducted with large-scale model samples, such as $500 \mathrm{~mm} \times 500 \mathrm{~mm} \times 500 \mathrm{~mm}$. Furthermore, a smooth structural plane is used in this study, while some scholars reported that the asperity shear of the structural plane may cause fault slip $[29,30]$. Therefore, further studies need to be focused on the influence of the attitude of structural planes on rockbursts, such as surface roughness, shape, and orientation. Moreover, the tunnels were performed in this test and the influence of excavation is not considered, which need to be addressed in the future. For the sake of simplicity, we just focused on the evolution process of fault-slip rockbursts. The evolution of buckling and shear rupture rockbursts can be investigated in future research. In this article, the strain fields of structural-type rockbursts are analysed using DIC technique, and the displacement fields can also be discussed in future research.

\section{Conclusions}

In this study, biaxial model tests were undertaken using marble samples to investigate the influence mechanism of the structural plane on rockbursts by considering different locations of structural planes, i.e., in tunnel spandrel, in tunnel sidewall, and at the intersection with the tunnel. The failure characteristics and rockburst evolution process were traced by the digital image correlation technique. The UDEC software was used for better understanding the ejection process of the fractured rock masses during rockbursts influenced by the structural plane. The following conclusions are obtained:

(1) The stress-strain curves can be divided into four main regions: elastic deformation region, stable crack propagation region, unstable crack propagation region, and postpeak region. The stress drop in the postpeak region can release the stored strain energy, which may induce the rockburst damage.

(2) The evolution process of fault-slip rockburst (buckling rockburst or shear rupture rockburst) experienced four main stages: quiet stage, crack initiation and propagation stage, shear slip stage (splitting and bending stage or shear rupture stage), and rockburst stage, which is corresponding with the four regions of stress-strain curves.

(3) The shear moving process of the structural plane can be traced by the digital image correlation technique, which demonstrates that the shear failure of the structural plane is the main cause resulting in the fault-slip rockburst. The UDEC software can better simulate the process of the fault-slip rockburst and the results show a very good agreement with the actual 11.28 rockburst.

\section{Data Availability}

The data supporting the findings of this study are available within the article.

\section{Conflicts of Interest}

No potential conflicts of interest were reported by the authors.

\section{Acknowledgments}

The financial supports for this research, from the Key Development Program for Research of Shandong Province (Grant no. 2018GNC110023) and the National Natural Science Foundation of China (Grant no. 51574156), are gratefully acknowledged.

\section{References}

[1] X. T. Feng, Rockburst: Mechanisms, Monitoring, Warning, and Mitigation, Butterworth-Heinemann, Oxfordshire, UK, 2017. 
[2] A. M. Naji, M. Z. Emad, H. Rehman, and H. Yoo, "Geological and geomechanical heterogeneity in deep hydropower tunnels: a rock burst failure case study," Tunnelling and Underground Space Technology, vol. 84, pp. 507-521, 2019.

[3] B. Li, R. Bao, Y. Wang, R. Liu, and C. Zhao, "Permeability evolution of two-dimensional fracture networks during shear under constant normal stiffness boundary conditions," Rock Mechanics and Rock Engineering, vol. 54, no. 3, pp. 1-20, 2021.

[4] Q. Wang, H. Gao, B. Jiang, S. Li, M. He, and Q. Qin, "In-situ test and bolt-grouting design evaluation method of underground engineering based on digital drilling," International Journal of Rock Mechanics and Mining Sciences, vol. 138, Article ID 104575, 2021.

[5] Q. Wang, Q. Qin, B. Jiang et al., "Mechanized construction of fabricated arches for large-diameter tunnels," Automation in Construction, vol. 124, Article ID 103583, 2021.

[6] C. Zhang, X.-T. Feng, H. Zhou, S. Qiu, and W. Wu, "Case histories of four extremely intense rockbursts in deep tunnels," Rock Mechanics and Rock Engineering, vol. 45, no. 3, pp. 275-288, 2012.

[7] T. J. Williams, C. J. Wideman, and D. F. Scott, "Case history of a slip-type rockburst," Pure and Applied Geophysics PAGEOPH, vol. 139, no. 3-4, pp. 627-637, 1992.

[8] W. D. Ortlepp and T. R. Stacey, "Rockburst mechanisms in tunnels and shafts," Tunnelling and Underground Space Technology, vol. 9, no. 1, pp. 59-65, 1994.

[9] B. G. White and J. K. Whyatt, "Role of fault slip on mechanisms of rock burst damage, Lucky Friday Mine, Idaho,USA," in Proceedings of the SARES 99: 2nd Southern African Rock Engineering Symposium. Implementing Rock Engineering Knowledge, pp. 169-178, T.O. Hagan, Johanessburg, South Africa, Septembet 1999.

[10] W. D. Ortlepp, "Observation of mining-induced faults in an intact rock mass at depth," International Journal of Rock Mechanics and Mining Sciences, vol. 37, no. 1-2, pp. 423-436, 2000.

[11] W. Blake and D. G. F. Hedley, Rockbursts: Case Studies from North American Hard-Rock Mines, Society for Mining, Metallurgy, and Exploration, Englewood, CO, USA, 2003.

[12] A. Li, F. Dai, Y. Liu, H. Du, and R. Jiang, "Dynamic stability evaluation of underground cavern sidewalls against flexural toppling considering excavation-induced damage," Tunnelling and Underground Space Technology, vol. 112, Article ID 103903, 2021.

[13] L. A. M. Castro, T. G. Carter, and N. Lightfoot, "Investigating factors influencing fault-slip in seismically active structures,", in Proceedings of the 3rd CANUS Rock Mechanics Symposium, Toronto, Canada, May 2009.

[14] C. Zhang, X.-T. Feng, H. Zhou, S. Qiu, and Y. Yang, "Rock mass damage induced by rockbursts occurring on tunnel floors: a case study of two tunnels at the Jinping II Hydropower Station," Environmental Earth Sciences, vol. 71, no. 1, pp. 441-450, 2014.

[15] H. Zhou, F. Meng, C. Zhang, D. Hu, F. Yang, and J. Lu, "Analysis of rockburst mechanisms induced by structural planes in deep tunnels," Bulletin of Engineering Geology and the Environment, vol. 74, no. 4, pp. 1435-1451, 2015.

[16] P. E. Snelling, L. Godin, and S. D. McKinnon, "The role of geologic structure and stress in triggering remote seismicity in Creighton Mine, Sudbury, Canada," International Journal of Rock Mechanics and Mining Sciences, vol. 58, pp. 166-179, 2013.
[17] A. Sainoki and H. S. Mitri, "Evaluation of fault-slip potential due to shearing of fault asperities," Canadian Geotechnical Journal, vol. 52, no. 10, pp. 1417-1425, 2015.

[18] A. Sainoki and H. S. Mitri, "Back analysis of fault-slip in burst prone environment," Journal of Applied Geophysics, vol. 134, pp. 159-171, 2016.

[19] A. Manouchehrian and M. Cai, "Analysis of rockburst in tunnels subjected to static and dynamic loads," Journal of Rock Mechanics and Geotechnical Engineering, vol. 9, no. 6, pp. 1031-1040, 2017.

[20] C. Zhu, M. He, M. Karakus, X. Zhang, and Z. Tao, "Numerical simulations of the failure process of anaclinal slope physical model and control mechanism of negative Poisson's ratio cable," Bulletin of Engineering Geology and the Environment, vol. 80, no. 4, pp. 3365-3380, 2021.

[21] Z. Tao, C. Zhu, M. He, and M. Karakus, "A physical modelingbased study on the control mechanisms of Negative Poisson's ratio anchor cable on the stratified toppling deformation of anti-inclined slopes," International Journal of Rock Mechanics and Mining Sciences, vol. 138, Article ID 104632, 2021.

[22] L. Obert and W. I. Duvall, Rock Mechanics and the Design of Structures in Rock, John Wiley \& Sons, New York, NY, USA, 1967.

[23] M. S. Diederichs, P. K. Kaiser, and E. Eberhardt, "Damage initiation and propagation in hard rock during tunnelling and the influence of near-face stress rotation," International Journal of Rock Mechanics and Mining Sciences, vol. 41, no. 5, pp. 785-812, 2004.

[24] C. D. Martin, The strength of massive Lac du Bonnet granite around underground openings, $\mathrm{PhD}$ thesis, University of Manitoba, Winnipeg, Canada, 1994.

[25] E. Eberhardt, D. Stead, B. stimpson, and R. S. Read, "Identifying crack initiation and propagation thresholds in brittle rock," Canadian Geotechnical Journal, vol. 35, no. 2, pp. 222-233, 1998.

[26] M. Cai, P. K. Kaiser, Y. Tasaka, T. Maejima, H. Morioka, and M. Minami, "Generalized crack initiation and crack damage stress thresholds of brittle rock masses near underground excavations," International Journal of Rock Mechanics and Mining Sciences, vol. 41, no. 5, pp. 833-847, 2004.

[27] Y. Wang, W. K. Feng, R. L. Hu, and C. H. Li, "Fracture evolution and energy characteristics during marble failure under triaxial fatigue cyclic and confining pressure unloading (FC-CPU) conditions," Rock Mechanics and Rock Engineering, vol. 54, no. 2, pp. 799-818, 2021.

[28] C. Zhang, X.-T. Feng, H. Zhou, S. Qiu, and W. Wu, "Rockmass damage development following two extremely intense rockbursts in deep tunnels at Jinping II hydropower station, southwestern China," Bulletin of Engineering Geology and the Environment, vol. 72, no. 2, pp. 237-247, 2013.

[29] J. A. Ryder, "Excess shear stress in the assessment of geologically hazardous situations," Journal of the Southern African Institute of Mining and Metallurgy, vol. 88, pp. 27-39, 1988.

[30] A. Sainoki and H. S. Mitri, "Simulating intense shock pulses due to asperities during fault-slip," Journal of Applied Geophysics, vol. 103, pp. 71-81, 2014. 